\title{
Research on Capacity Coordination of Loading and Unloading Wagon Flow on Heavy-Haul Railway
}

\author{
Hanxiao Zhou ${ }^{1, \text { a }}$, Leishan Zhou ${ }^{1, b}$ and Jinjin Tang ${ }^{1, c^{*}}$ \\ ${ }^{1}$ School of Traffic and Transportation, Beijing Jiaotong University \\ No.3 Shang Yuan Cun, Hai Dian District, Beijing, China.100044 \\ a15120935@bjtu.edu.cn, ${ }^{b}$ Ishzhou@bjtu.edu.cn, ${ }^{c}$ jjtang@bjtu.edu.cn
}

\begin{abstract}
Keywords: railway transportation; coordination of loading and unloading wagon flow; multi-object programming problem; transportation problem

Abstract. This paper has carried out some researches on organization method of wagon flow of coal transportation corridor to meet the demand of heavy-haul railway. To improve the capacity of a collecting and distributing system, the optimal problem is described as: coordination of loading capacity and unloading capacity to determine the wagon flow. Based on the analysis of the capacity of loading end and unloading end of Daqin Railway, the model with the minimization of the transportation price and the idle cost of the equipment and the maximization of the total loading and unloading wagons of the system is constructed. Then the paper transformed this multi-objective programming into a transportation problem by using main objective method, so that the model can be solved easily. Finally, by solving of the problem respectively on Daqin Railway, the model is proved to use on capacity coordination of loading and unloading stations on heavy-haul railway.
\end{abstract}

\section{Introduction}

Heavy-haul and high-speed are the two major trends in the development of railway transportation, among which high-speed is the trend of passenger transportation and heavy-haul is the trend of freight transportation, especially the mass freight tansport. For heavy haul transportation, experts have done a lot of research, such as Ciguang Wang [1] using multi-objective planning to study the problem of heavy haul trains, taking the line capacity, the number of locomotive and wagons into the limit of the heavy haul transportion organization. According to the characteristics of heavy haul train station, Jinchuan Zhang [2] has analyzed station type and the characteristics and process of the train station, and proposed the calculation method of the capacity of heavy haul train combined station. Han Xuesong [3, 4] divides loading end of heavy haul railway into different level, and minimize the total combined time and travel time to optimizes the combination operation organization scheme, and constructs the nonlinear 0-1 programming model to solve the problem. This paper focused on the capacity coordination of loading and unloading station in a heavy-haul transportation system, and match the wagon flow of this collecting and distributing railway system.

Daqin Railway is China's first double-tracking and electrification coal transportation corridor. Since its opening, Daqin Railway continued expansion and renovation to improve its transportation organization ability. With the 10kt heavy haul unit train and 20kt heavy haul trains putting into operation, the traffic volume of Daqin Railway has been greatly improved. However, with the continuous development of the national economy, the demand for coal is still higher than the actual transport capacity of Daqin Railway. Under the existing transportation organization, coordinate the capacity of loading and unloading station can plays an important role to reduce transportation cost and enhance the transportation efficiency of Daqin Railway and also laid the foundation for further expansion.

\section{Analysis}

According to the actual geographical conditions and the layout of Daqin line, the loading end and unloading end of the line were simplified to a certain number of loading base and unloading base, as shown in Fig.1, 
which contain a certain condition of equipment and operation ability. Based on the actual data of actual cargo handling equipment conditions, the loading and unloading capacity of Daqin Railway can be analyzed and calculated.

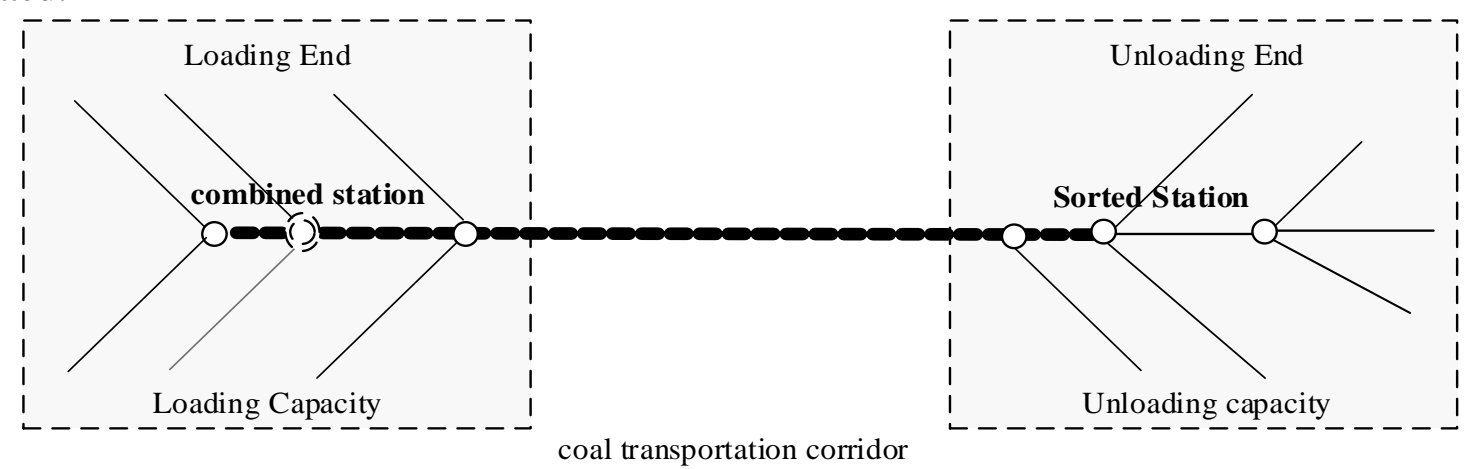

Fig. 1. Simplified schematic of Daqin Railway transportation system

The capacity of total loading bases, total unloading bases and the railway line of Daqin Railway are shown in table 1.

Table 1. Capacity of total loading based and unloading bases (wagon/d)

\begin{tabular}{ccc}
\hline Capacity of total loading bases & Capacity of railway line & Capacity of total unloading bases \\
\hline 51579 & 18228 & 25175 \\
\hline
\end{tabular}

It can be easily found in the Table 1 that the most minimum capacity of the Daqin Railway collecting and distributing system is the capacity of the railway line, and the second one is the capacity of total unloading bases. So the capacity of the railway line is the bottleneck of the whole collecting and distributing system. That means the system's capacity can be improved by improving the railway line's capacity. Based on this, a way that by improving train traction weight and partly operating $3 \mathrm{kt}$ combined train to improve the system's capacity has been put forward on Daqin Railway. But organizing the $3 \mathrm{kt}$ combined train must based on the condition that the wagon flow of the loading end and the unloading end has been well organized. Therefore, this paper focuses on how to determine the wagon flow from each loading base to unloading base.

In this paper, the capacity coordination of loading end and unloading end of heavy-haul transportation is defined as this: in a given road network environment with certain loading and unloading equipment condition, to balance the loading capacity and unloading capacity by determining the wagon flow between each loading base and unloading base. Meanwhile minimize the total cost of transportation.

\section{Model}

In one coal collection and distribution system, there are some coal loading bases with known loading capacity; the directions of coal are some coal unloading bases with known unloading capacity. The total capacity of loading bases is larger than the unloading ones. Aimed at minimizing transport expense, an optimal transport plan needs to be drawn out with the known distance between each loading and unloading base.

The relevant variables in the model of determining wagon flow based on handling capacity coordination are as follows: The quantity of loading bases is $m$, denoted by the set $A=\left\{a_{1}, a_{2}, \ldots, a_{i}, \ldots, a_{m}\right\}$, with the each loading capacity denoted by the set $L=\left\{l_{1}, l_{2}, \ldots, l_{i}, \ldots, l_{m}\right\}$; The quantity of unloading bases is $n$, denoted by the set $B=\left\{b_{1}, b_{2}, \ldots, b_{j}, \ldots, b_{m}\right\}$, with the each unloading capacity denoted by the set $U=\left\{u_{1}, u_{2}, \ldots, u_{j}, \ldots, u_{n}\right\}$; Equipment idle cost will be produced when the loading capacity has not been satisfied. For loading base $a_{i}$, the idle cost of per unit of goods is $s_{i}$, denoted by the set $S=\left\{s_{1}, s_{2}, \ldots, s_{i}, \ldots, s_{m}\right\}$. The total cost is $s_{i}\left(l_{i}-\sum_{j} x_{i j}\right)$.

decision variables of model

$x_{i j}$ : The quantity of wagons from loading base $a_{i}$ to unloading base $b_{j} ;$ as an integer. 


\section{model parameter}

$Z:$ total transport cost, wagon-kilometers.

$Q:$ total freight amount of coal collection and distribution transportation system, wagon/day

In one coal collection and distribution system.

$c_{i j}$ : freight rates for transporting per-unit coal from loading base $a_{i}$ to unloading base $b_{j}$; expressed by transport distant.

$s_{i}:$ equipment idle cost when the loading capacity has not been satisfied.

$l_{i}:$ the daily loading capacity of base $A_{i}$, wagon/day.

$u_{j}$ : the daily unloading capacity of base $B_{j}$, wagon/day.

Hence, the mathematical model of station- station handling capacity coordination is set up as follows:

$$
\begin{aligned}
& \min Z=\sum_{i=1}^{m} \sum_{j=1}^{n} c_{i j} x_{i j}+\sum_{i=1}^{m} s_{i}\left(l_{i}-\sum_{j=1}^{n} x_{i j}\right) \\
& \max Q=\sum_{i=1}^{m} \sum_{j=1}^{n} x_{i j}
\end{aligned}
$$

s.t.

$$
\begin{aligned}
& \sum_{i=1}^{m} x_{i j} \leq u_{j} \quad j=1,2, \cdots, n \\
& \sum_{j=1}^{n} x_{i j} \leq l_{i} \quad \mathrm{i}=1,2, \cdots, \mathrm{m} \\
& x_{i j} \geq 0 \quad \forall i, j
\end{aligned}
$$

Where, Eq. 1、Eq. 2 refer to Objective function. Eq. 1 limits the minimum transport expense; Eq. 2 limits maximum freight amount in coal collection and distribution transportation system; Eq. 3 show that the quantity of wagons from the loading bases must meet the loading capacity; Eq. 4 show that the quantity of wagons from the unloading bases must meet the unloading capacity; Eq. 5 considers that each flow between each loading and unloading base must be a nonnegative integer.

\section{Solution method}

The models in the last chapter are multi-objective programming. For facilitating solving and keeping the accuracy of the results, this paper transform the traffic flow model into a classical transportation problem. The scheme model of heavy haul trains is transformed into a single objective program according to the actual characteristics.

According to the listed model, this is a multi-objective integer programming model, applied for coal transportation organization. While in the actual transportation process, China's coal loading capacity is greater than the unloading capacity, and the coal supply will not be greater than the demand for coal. In order to match the capacity of loading and unloading bases of the Datong Qinhuangdao railway to the maximum extent possible, the quantity of unloading wagons received by every unloading bases could set to be equal to its unloading capacity.

$$
\sum_{i=1}^{m} x_{i j}=u_{j} \quad j=1,2, \cdots, n
$$


By the above transformation, the original model was transformed into:

$$
\begin{aligned}
& \min Z=\sum_{i=1}^{m} \sum_{j=1}^{n} c_{i j} x_{i j}+\sum_{i=1}^{m} s_{i}\left(l_{i}-\sum_{j=1}^{n} x_{i j}\right) \\
& \sum_{i=1}^{m} x_{i j}=u_{j} \quad j=1,2, \cdots, n \\
& \sum_{j=1}^{n} x_{i j} \leq l_{i} \quad \mathrm{i}=1,2, \cdots, \mathrm{m} \\
& x_{i j} \geq 0 \quad \forall i, j
\end{aligned}
$$

Thus, the original problem is converted to a single objective linear programming.

For the objective function Eq. 7, transformation can continue to be converted to:

$$
\begin{aligned}
& \min Z=\sum_{i=1}^{m} \sum_{j=1}^{n} c_{i j} x_{i j}-\sum_{i=1}^{m} \sum_{j=1}^{n} s_{i} x_{i j}+\sum_{i=1}^{m} s_{i} l_{i} \\
& \min Z=\sum_{i=1}^{m} \sum_{j=1}^{n}\left(c_{i j}-s_{i}\right) x_{i j}+\sum_{i=1}^{m} s_{i} l_{i}
\end{aligned}
$$

After transformation, in objective function Eq. 12, $\sum_{i=1}^{m} s_{i} l_{i}$ turns into a constant; $\sum_{i=1}^{m} \sum_{j=1}^{n}\left(c_{i j}-s_{i}\right) x_{i j}$ can be considered as a target function of a transport problem. Therefore, the model turns into an unbalanced transportation problem.

For a classical transportation problem, the Table Operations Method could be used [5]. Then introduce a slack variables in the constraint conditions Eq. 9 of the model

$$
\sum_{j=1}^{n} x_{i j}+x_{i(n+1)}=l_{i} \quad i=1,2, \cdots, \mathrm{m}
$$

Then, invent a dummy unloading base $b_{n+1}$ with the capacity $u_{n+1}$ :

$$
u_{n+1}=\sum_{i=1}^{m} l_{i}-\sum_{j=1}^{n} u_{j}
$$

Treat the slack variables $b_{n+1}$ as the wagon flow from $a_{i}$ to $b_{n+1}$ with the freight rates $c_{i(n+1)}=0(i=1,2, \ldots, m)$. Now the original model has been transformed into a transportation problem with the balance of production and marketing.

In addition, since we transform the multi-objective model into a single objective model, and go a step further into the classical transport problem, therefore, current optimization software can be directly used for solving the model, such as GAMS.

GAMS(General Algebraic Modeling System)is a high-level language user interface, which was developed by Meeraus and Brooke.

With the help of GAMS, the optimization model can be established easily and modified further. The input file would become one format which is acceptted by a lower order optimization numerical algorithm program after compiled, and then perform and write output file.

\section{Solution}

According to the actual situation of Daqin Line, calculate and determine the parameter values including the loading capacity $l_{i}$ of loading bases, unloading capacity $u_{j}$ of unloading bases and transportation costs $c_{i j}$. 
Then computation of the economical and rational wagon flow between different loading and unloading bases is carried out using values obtained above with GAMS.

Model input. Table 2 shows the loading capacity $l_{i}$ of loading bases, and unloading capacity $u_{j}$ of unloading bases :

Table 2 Capacities of loading and unloading base

\begin{tabular}{|c|c|c|c|}
\hline \multicolumn{2}{|c|}{ Loading capacity $l_{i}$ (wagon/day) } & \multicolumn{2}{|c|}{ unloading capacity $u_{j} \quad($ wagon/day $)$} \\
\hline loading bases & Loading capacity & loading bases & unloading capacity \\
\hline HanJialing- Yuanping Line & 15058 & $\mathrm{Cha} \mathrm{Wu}$ & 382 \\
\hline Northern Tongpu Railway & 18888 & Dashi Zhuang & 870 \\
\hline Yungang Branch & 2365 & Jixian West & 403 \\
\hline Kouquan Branch & 1134 & Cui Ping Shan & 960 \\
\hline Datong-Baotou Line & 6845 & Zunhua North & 1296 \\
\hline \multirow[t]{6}{*}{ Datong- Zhunge'er Line } & 7289 & Qian'an North & 480 \\
\hline & & Caofeidian West & 4992 \\
\hline & & Dong Gang & 1944 \\
\hline & & Luan Nan & 4584 \\
\hline & & Hou Ying & 2544 \\
\hline & & Liucun South & 6720 \\
\hline
\end{tabular}

Freight rates $c_{i j}$ : Transport cost is calculated by its transport distance, $c_{i j}=d_{i j}$, as shown in Table 3 .

Table 3 Distance matrix of loading and unloading base

\begin{tabular}{ccccccc}
\hline $\begin{array}{c}\text { Transport } \\
\text { Distance } \\
d_{i j}\end{array}$ & $\begin{array}{c}\text { HanJialing- } \\
\text { Yuanping } \\
\text { Line }\end{array}$ & $\begin{array}{c}\text { Northern } \\
\text { Tongpu } \\
\text { Railway }\end{array}$ & $\begin{array}{c}\text { Yungang } \\
\text { Branch }\end{array}$ & $\begin{array}{c}\text { Kouquan } \\
\text { Branch }\end{array}$ & $\begin{array}{c}\text { Datong-Baoto } \\
\text { u Line }\end{array}$ & $\begin{array}{c}\text { Datong- } \\
\text { Zhunge'er } \\
\text { Line }\end{array}$ \\
\hline Cha Wu & 604 & 406 & 358 & 353 & 504 & 466 \\
Dashi Zhuang & 665 & 467 & 419 & 414 & 565 & 527 \\
Jixian West & 678 & 480 & 432 & 427 & 578 & 540 \\
Cui Ping Shan & 689 & 491 & 443 & 438 & 589 & 551 \\
Zunhua North & 748 & 550 & 502 & 497 & 648 & 610 \\
Qian'an North & 826 & 628 & 580 & 575 & 726 & 688 \\
Caofeidian & 963 & 765 & 717 & 712 & 863 & 825 \\
West & 941 & 743 & 695 & 690 & 841 & 803 \\
Dong Gang & 897 & 699 & 651 & 646 & 797 & 759 \\
Luan Nan & 917 & 719 & 671 & 666 & 817 & 779 \\
Hou Ying & 915 & 717 & 669 & 664 & 815 & 777 \\
Liucun South & 917 & & &
\end{tabular}


Output results. The economical and rational wagon flow between different loading and unloading bases are listed in the Table 4.

Table 4 Results of cargo flow between the loading and unloading base (wagon/day)

\begin{tabular}{|c|c|c|c|c|c|c|c|c|c|c|c|}
\hline & $\begin{array}{l}\text { Cha } \\
\mathrm{Wu}\end{array}$ & $\begin{array}{c}\text { Dashi } \\
\text { Zhuang }\end{array}$ & $\begin{array}{l}\text { Jixian } \\
\text { West }\end{array}$ & $\begin{array}{l}\text { Cui Ping } \\
\text { Shan }\end{array}$ & $\begin{array}{l}\text { Zunha } \\
\text { North }\end{array}$ & $\begin{array}{c}\text { Qian'an } \\
\text { North }\end{array}$ & $\begin{array}{c}\text { Caofeidian } \\
\text { West }\end{array}$ & $\begin{array}{l}\text { Dong } \\
\text { Gang }\end{array}$ & $\begin{array}{c}\text { Luan } \\
\text { Nan } \\
\end{array}$ & $\begin{array}{l}\text { Hou } \\
\text { Ying }\end{array}$ & $\begin{array}{l}\text { Liucun } \\
\text { South } \\
\end{array}$ \\
\hline HanJialing- & & & & & & & & & & & \\
\hline $\begin{array}{l}\text { Yuanping } \\
\text { Line }\end{array}$ & - & - & - & - & - & - & - & - & - & - & - \\
\hline $\begin{array}{c}\text { Northern } \\
\text { Tongpu } \\
\text { Railway }\end{array}$ & 382 & 870 & 403 & 960 & 1296 & 480 & 91 & - & 2881 & 179 & - \\
\hline $\begin{array}{l}\text { Yungang } \\
\text { Branch }\end{array}$ & - & - & - & - & - & - & - & - & - & $\begin{array}{c}236 \\
5\end{array}$ & - \\
\hline $\begin{array}{c}\text { Kouquan } \\
\text { Branch }\end{array}$ & - & - & - & - & - & - & - & - & - & - & 1134 \\
\hline $\begin{array}{c}\text { Datong- } \\
\text { Baotou Line } \\
\text { Datong- }\end{array}$ & - & - & - & - & - & - & 4901 & 1944 & - & - & - \\
\hline $\begin{array}{l}\text { Zhunge'er } \\
\text { Line }\end{array}$ & - & - & - & - & - & - & - & - & 1703 & - & 5586 \\
\hline
\end{tabular}

\section{Conclusion}

The paper has done some research on cargo flow organization of heavy haul railway, and proposed to come up with a specific organizational method that can optimize the efficiency of the entire collection and distribution system and reduce the transportation costs. Based on that the model with the minimization of the transportation price and the idle cost of the equipment and the maximization of the total loading and unloading volume of the nodes and line is constructed. Then the paper transformed this multi-objective programming into a single objective programming by using main objective method combined with the actual situation of cases in order to find an optimum solution easily. The method proposed in this paper can effectively optimize the wagon flow organizations of coal transportation corridor, and provides the foundation for compiling the train planning of the heavy haul railway. Meanwhile, the model transformation and solution method for solving multi-objective proposed programming also provides a reference.

\section{Acknowledgements}

In this paper, the data is offered by Taiyuan Railway Administration, and the research is supported by China Railway Corporation under grant No.2014X001-B "Transportation Scheduling Optimization for 30kt Combined Train on Daqin Railway".

\section{References}

[1] Ciguang Wang, Appilication of goal programming in railway heavy haul transportation, Journal of Southwest Jiaotong University, 44(3) (2009) 392-395. ( In Chinese)

[2] Peng Zhao, Jinchuan Zhang, Baogang Tang, Research on the optimization model of train flow organization in heavy haul railway loading area based on combined train, China railway science, 31(6) (2010) 116-121. (In Chinese)

[3] Xuesong Han Jun Zhao, Qiyuan Peng, Optimization of Train Flow Combination Scheme for Strategic Heavy Hual Loading Domain at Multi-combination Stations, Journal of the China railway society, 34(8) (2012) 1-6. (In Chinese) 
[4] Xuesong Han, Hongyang Guo, Qiyuan Peng, Methods for Optimization of Combination Schemes of Combination Stations in Heavy-haul Transportation, Journal of the China railway society, 34(12) (2012) 1-7. (In Chinese)

[5] Guangming Wang, Linmao Ma, Lanlan Li, Algorithm and Extended Research in Solving Transportation Problems, Journal of Yangtze University(Natural Science Edition), 08 (2011) 1-5. (In Chinese) 